\title{
Health status and quality of life of female garment workers in Sri Lanka
}

\author{
De Silva PV ${ }^{1,2}$, Lombardo $S^{2}$, Lipscomb $H^{3}$, Grad $J^{4}$, Østbye $T^{4}$ \\ ${ }^{\prime}$ Department of Community Medicine, Faculty of Medicine, University of Ruhuna, Galle, Sri Lanka. \\ ${ }^{2}$ Duke Global Health Institute, Duke University, Durham, NC27708, USA. \\ ${ }^{3}$ Division of Occupational and Environmental Medicine, Duke University Medical Center, Durham, NC 27710 \\ USA, ${ }^{4}$ Department of Community and Family Medicine and Duke Global Health Institute, Duke University, \\ Durham, NC 27710, USA
}

Correspondence: Dr.P.V. de Silva (pvijithadesilva123@yahoo.com)

\begin{abstract}
Objectives: The garment industry has gradually become the major foreign exchange earner in Sri Lanka. The objective of this study is to provide an overview of health problems and quality of life among female garment workers in Sri Lanka.

Methods: A random sample of female garment workers in the Free Trade Zone in Koggala, Sri Lanka was recruited. Information on medical symptoms and health related quality of life (WHO QOL) was collected through interviews conducted by medically qualified research assistants using a structured questionnaire.

Results: A total of 1058 female workers participated in the study. Mean age was 27.8 years, Musculoskeletal problems were reported by $15.5 \%$, the most prevalent complaint being lower back problems. Over $5 \%(n=59)$ reported a workplace injury in the last year; most of these $(68.3 \%)$ were puncture injuries. Very few $(n=5 ; 0.5 \%)$ reported having been subjected to emotional abuse, and none reported any sexual or physical abuse at work during the last 12 months. Most $(\mathrm{n}=576 ; 54.4 \%)$ rated their overall quality of life as very good or good, and $63.8 \%(n=676)$ were satisfied with their health. Scores relating to psychological complaints were lower (worse) than those for physical complaints.

Conclusion: Relative to studies of other occupational groups in middle income countries, these female garment workers reported overall good health; their most notable problem was musculoskeletal symptoms. The findings could represent adequate control of work-related risks, but a healthy worker effect and social desirability bias must also be considered as explanations for the positive health status of these relatively young workers.
\end{abstract}

Keywords: Garment workers, Female, Health Status, Quality of Life, Occupational Health, Sri Lanka

\section{Introduction}

In the late 1970s Sri Lanka changed from socialist to more of a market economy, encouraging export oriented trade and foreign investment (1). As a result of this increasingly open economy Free Trade Zones (FTZ) were opened and tax exemptions provided to encourage foreign investment and technology transfer to the country. While initially FTZ were established close to the capital Colombo, later they were also established in rural areas to reduce problems associated with migration and urbanization. The garment industry has become the largest contributor of export revenue, surpassing traditional exports such as tea, rubber and coconut (2), and it currently employs several hundred thousand workers in Sri Lanka; the majority being young women (2). The garment industry plays a vital role in providing employment to rural, less educated 
females, and the economic liberalization that has occurred in Sri Lanka in the last three decades has significantly altered traditional gender norms, allowing women to take on new roles as an independent wage-earner and sometimes as primary breadwinners for their families (3).

The FTZ in Koggala in the Southern part of Sri Lanka, near the port city of Galle, encompasses twenty factories, fifteen of these manufacture garments and/or textiles. These factories employ 10,211 people, seventy-five percent $(7,622)$ of whom are women. Prior studies report most of these women to be young, single, relatively poorly educated, and hailing from rural areas $(4,5)$.

The workers are under pressure to keep up with the production demands, working long shifts, at night and overtime (6). To achieve production targets, the workers usually operate machinery continuously at one specified place in the production line. The garment workers work as seamstresses (operating sewing machines), ironers (operating ironing machines) or quality assessment assistants (assessing the products for defects). The quality assessment workers stand throughout their shifts. The effects of long work-hours and monotonous, stressful work can be deleterious to both mental and physical health (7). The women are paid approximately 15,000 Rupees (\$140 US dollars) per month. This is comparable to what nurses, teachers or clerks are paid for working forty hours a week, but the garment workers have much longer hours with shifts usually lasting from 7.00 am to 5.00 pm or from $5.00 \mathrm{pm}$ to 7.00 am six days a week. Occasionally the garment workers work from 7.00 am to $10.00 \mathrm{pm}$ or overnight in order to meet deadlines.

Studies from both Sri Lanka and abroad have identified numerous health problems among industrial workers in general and garment workers in particular $(7,8)$. Due to the physical demands and the repetitive nature of their work, factory workers are especially susceptible to musculoskeletal disorders [8]. Pain in the back and large joints such as the knee and shoulder joints are among the most common health complaints in industrialized societies (8). These problems are even more common among females (9) and older workers (10); they are a major reason for absence and workplace attrition, and can be costly both for the worker and for the industry (11). Respiratory symptoms among female garment factory workers, involved in later stages of garment production, are often nondescript, and rarely indicate a distinct disease entity in contrast to byssinosis or 'brown lung' disease that is associated with initial stages of cotton processing (12-15). Accidents, headaches, dermatological problems have also been identified as problems among garment workers elsewhere by factory nurses and by primary care physicians working in the Koggala area. However these problems have not been systematically studied among garment workers of Sri Lanka. The aim of this study was therefore to assess the nature and extent of health problems and the quality of life experienced by female garment workers in FTZ Koggala, Sri Lanka.

\section{Methods}

This investigation was conducted in two phases using both qualitative and quantitative approaches. In the first, qualitative phase, four focus groups were conducted with 24 female garment workers employed in factories in the Koggala Free Trade Zone. The women were interviewed in groups of six. Only the women who had worked in a garment factory for at least six consecutive months were included in the focus groups. The focus groups identified musculoskeletal pain, accidental injuries, respiratory problems, dermatological problems and headaches to be of concern.

The second, quantitative, phase of the study is the main focus of this manuscript. This phase was a cross-sectional survey, designed based on the findings from the focus group discussions. The survey included two questionnaires. An interviewer administered questionnaire was first used to collect data on socio-demographic factors, occupational health problems and physical, verbal and sexual harassments in the work place among garment workers and a self administered questionnaire was then used to collect data on quality of life using World Health Organization Quality Of Life Brief questionnaire (WHO QOL) (16). A total of 7622 female garment workers are employed in the FTZ Koggala. One thousand and sixty seven female workers were randomly selected to the study based 
on the pay register and recruited to the study. The number of workers selected from each factory was proportionate to the total number of female workers in that factory. Two medically qualified research assistants administered the first questionnaire in a private room. Subsequently, a self administered questionnaire which consisted with the WHO QOL Brief questionnaire was completed by the workers themselves and collected by the research assistants.

Data were coded and entered into Epinfo. After data cleaning and checking, tabulations were carried out using Stata in order to describe the population and the prevalence of the conditions of interest.

Ethical clearance was obtained from both from the Ethical Review Committee of Faculty of Medicine,
University Ruhuna, Sri Lanka and from the Duke University Medical Center Institutional Review Board. Informed written consent was obtained from all study participants.

\section{Results}

Out of the 1067 workers who agreed to participate, 1058 completed the survey, i.e. a response rate over $99 \%$. More than two thirds $(67.5 \%)$ were younger than 30 years, and most worked as sewing machine operators. Most (87.2\%) were educated up to General Certificate of Education ordinary level (at the end of grade 11 in school education) or above, and more than half $(53.8 \%)$ had worked in the garment field for less than five years (Table 1).

Table 1: Socio-demographic characteristics of the participating female Sri Lankan garment workers $(\mathrm{n}=1058)$

\begin{tabular}{lrrrr}
\hline & \multicolumn{4}{c}{ Frequency } \\
\cline { 2 - 5 } & N & \% & Mean & SD \\
\hline Age $(\mathrm{yr})$ & & & 27.8 & 7.3 \\
BMI $\left(\mathrm{kg} / \mathrm{m}^{2}\right)$ & & & 20.9 & 3.6 \\
\hline Job type & & & & \\
Sewing machine operator & 674 & 63.7 & & \\
Quality control assistant & 106 & 10.0 & & \\
Ironer, packer, cutter, other & 220 & 20.8 & & \\
Recorder, helper, supervisor & 58 & 5.5 & & \\
\hline Education & & & & \\
Grade 10 or below & 135 & 12.8 & & \\
O level & 641 & 60.6 & & \\
A level, post-secondary, other & 282 & 26.7 & & \\
\hline Time in industry (months) & & & 63.8 & 49.5 \\
\hline Monthly income (LKR) & & & 9629 & 2029 \\
Residence & & & & \\
\multicolumn{1}{c}{ Family home } & 904 & 85.4 & & \\
\multicolumn{1}{c}{ Other } & 154 & 14.6 & \\
\hline Total & $\mathbf{1 0 5 8}$ & $\mathbf{1 0 0 . 0}$ & & \\
\hline
\end{tabular}


In the last year, musculoskeletal problems were reported by $15.5 \%(n=164)$ of these workers; among those with musculoskeletal problems, $57.3 \%(n=94)$ complained of back pain. Musculoskeletal problems were more common with increasing age and BMI. Almost 8\% $(n=80)$ reported headaches, and of these, $70 \%(\mathrm{n}=56)$ were identified as having tension headache. Less than six percent $(5.6 \%, \mathrm{n}=59)$ reported having met with a work-related injury during the previous 12 months and, of these, only $10.2 \%(\mathrm{n}=6)$ had taken leave due to the injury. Sewing machine operators had the highest reported prevalence $(7.43 \%)$ of injuries - most of these events involved puncture wounds to the fingers only. Reports of emotional abuse were rare $(0.5 \%, \mathrm{n}=5)$ and none of the women reported physical or sexual abuse at work during last 12 months (Table 2).

Table 2: Twelve month prevalence of reported health problems, female Sri Lankan garment workers $(\mathrm{N}=\mathbf{1 0 5 8})$

\begin{tabular}{|c|c|c|c|}
\hline & \multicolumn{2}{|c|}{$\begin{array}{c}\text { Workers reporting } \\
\text { each problem }\end{array}$} & \multirow{2}{*}{$\begin{array}{r}\text { Subgroup } \\
\%\end{array}$} \\
\hline & $\mathrm{N}$ & $\%$ & \\
\hline \multicolumn{4}{|l|}{ Musculoskeletal } \\
\hline Total (individuals) & 164 & 15.5 & \\
\hline Hand / wrist & 12 & 1.1 & 7.3 \\
\hline Forearm / elbow & 5 & 0.5 & 3.0 \\
\hline Shoulder & 15 & 1.4 & 9.1 \\
\hline Knee & 52 & 4.9 & 31.7 \\
\hline Neck & 11 & 1.0 & 6.7 \\
\hline Back & 94 & 8.9 & 57.3 \\
\hline \multicolumn{4}{|l|}{ Respiratory } \\
\hline Wheezing & 36 & 3.4 & $\mathrm{~N}=36$ \\
\hline Wheezing + breathlessness & 32 & 3.0 & 88.9 \\
\hline Tightness in chest & 17 & 1.6 & 47.2 \\
\hline SOB attack at rest (last $12 \mathrm{mo}$ ) & 17 & 1.6 & 47.2 \\
\hline Exposure to fumes & 2 & 0.2 & 5.6 \\
\hline \multicolumn{4}{|l|}{ Headache } \\
\hline All headaches & 80 & 7.6 & $\mathrm{~N}=80$ \\
\hline Migraine & 24 & 2.3 & 30.0 \\
\hline Tension & 56 & 5.3 & 70.0 \\
\hline \multicolumn{4}{|l|}{ Accidents } \\
\hline Work accident involved during last 12 months & 59 & 5.6 & $\mathrm{~N}=59$ \\
\hline Avg. no. accidents per reporter & 2.4 & \multicolumn{2}{|c|}{$\begin{array}{l}\text { Median } 2, \text { mode } 1, \\
\text { range } 1-10\end{array}$} \\
\hline Received treatment & 26 & 2.5 & 44.1 \\
\hline Take off work b / c of injury & 6 & 0.6 & 10.2 \\
\hline \multicolumn{4}{|l|}{ Dermatology } \\
\hline Any skin symptom in last 3 months & 23 & 2.2 & $\mathrm{~N}=23$ \\
\hline Rashes & 17 & 1.6 & 73.9 \\
\hline Lesions & 1 & 0.1 & 4.3 \\
\hline Infection & 4 & 0.4 & 17.4 \\
\hline Scaling & 0 & 0 & 0 \\
\hline Physical abuse & 0 & 0 & \\
\hline Emotional abuse & 5 & 0.5 & \\
\hline Sexual abuse & 0 & 0 & \\
\hline
\end{tabular}


Most (54.4\%) women rated their overall quality of life as either very good or good; $63.8 \%$ were satisfied with their health. The highest (best) average score
70.2 (SD 14.9) was reported for the physical domain whereas the lowest score 42.5 (SD 12.0) was reported for the psychological domain (Table 3).

Table 3: Quality of life (WHO QOL) among the garment workers) $(\mathrm{N}=1058)$

\begin{tabular}{lccccc}
\hline \multicolumn{5}{c}{ Overall Quality of Life and Health Satisfaction } \\
& $\begin{array}{c}\text { Very good } \\
\text { or satisfied }\end{array}$ & $\begin{array}{c}\text { Good or } \\
\text { satisfied }\end{array}$ & Neither & $\begin{array}{c}\text { Poor or } \\
\text { dissatisfied }\end{array}$ & $\begin{array}{c}\text { Very poor } \\
\text { or } \\
\text { dissatisfied }\end{array}$ \\
\hline Quality of life & $18.4 \%(195)$ & $36.0 \%(381)$ & $44.9 \%(475)$ & $0.5 \%(5)$ & $0.2 \%(2)$ \\
Health satisfaction & $16.3 \%(173)$ & $47.5 \%(503)$ & $31.5 \%(333)$ & $4.2 \%(44)$ & $0.5 \%(5)$ \\
\hline & Mean & WHOQOL Domain Results & \\
\hline Physical & 70.2 & SD & Min & Max \\
Psychological & 42.5 & 14.9 & 29 & 100 \\
Social & 57.5 & 25.0 & 8 & 100 \\
Environment & 64.6 & 14.1 & 0 & 100 \\
\hline
\end{tabular}

\section{Discussion}

The present study describes the prevalence of several key health problems and quality of life among the female garment workers employed in the FTZ Koggala, Sri Lanka.

As expected, musculoskeletal disorders were identified as the most prevalent (15.5\%) health problem among these workers consistent with previous studies of female garment workers in other countries such as Bangladesh, India, Fiji and Lithuania $(7,8,17,18)$. However, the reported prevalence figures in other studies range from $12 \%$ to $80 \%$, with the prevalence in the present study is at the lower end of this range. A very low proportion $(3.4 \%)$ of the workers reported respiratory symptoms.

In the focus groups, headaches such as migraine and tension type were identified as important problems. We therefore tried to document these problems in some detail using the translated and validated Headache History Questionnaire (HHQ) (19). However, only $2.3 \%$ of workers reported migraine and $5.3 \%$ tension headache. We were not able to identify studies of headache in similar workers from the literature, but a community-based study conducted in the Western Province of Sri Lanka using the same HHQ identified much higher prevalence of migraine and tension headache (19). Relatively few workers reported work-related injuries in the last year, but it is of note that a number of those who did had more than one injury. Sewing machine operators was the group with the highest reported prevalence $(7.43 \%)$ of accidents. As expected, most of these were puncture wounds to the fingers. Similarly, Ind and Jeffries (1999) have reported prevalence of puncture wounds among the clothing industry workers of UK as $2.8 \%$. Harassment including emotional, physical and sexual abuse have rarely been reported by garment factory workers, and in the present study we also found little evidence of such. Most (54.4\%) of the workers rated their overall quality of life as either very good or good, and $63.8 \%$ were satisfied with their health.

In general, these garment workers in Sri Lanka appear to be healthier than similar workers in other developing countries: their reported QOL was quite high. There are a number of possible reasons for these findings. On the one hand, close supervision by 
the Sri Lanka Board of Investments and by preventive health workers may have contributed to these results. Almost all the factories employ at least one visiting doctor for the workers. All the factories in this FTZ are adhering to minimum standards and labor regulations adopted by Sri Lanka. Most of the textiles manufactured are exported to the US and Europe, and many of the larger buyers provide guidelines regarding provisions for health and social welfare of workers. For example, most of the factories in the FTZ Koggala have good ventilation systems and the indoor environments are regularly monitored by government health and environment officers. In addition, the financial independence achieved through the work may also contribute to the higher QOL observed (3). Furthermore, most of the factories organize different activities such as sports events New Year festivals, musical shows and annual excursions to boost worker satisfaction.

Alternative explanations for our findings should be considered as well. The comparatively high education level of Sri Lankan females relative to workers in other countries, their younger age and the shorter time they have worked in the industry may have contributed to the positive findings. The garment factories in Koggala are engaged in later stages of garment production, and consequently exposure to cotton dust would be less of a problem than in early production areas where workers might be more likely to have exposure to inhaled endotoxins. Respiratory symptoms are also more common among current smokers $(15,20)$, but smoking among females is very uncommon in Sri Lanka.

Under reporting of acute injuries, particularly those of a more minor nature, is likely women working with sewing machines may consider smaller punctures to be such an integral part of their work that they do not consider them important enough to report. Social desirability bias and possibly also a fear of retribution may partly explain the lack of more sensitive psycho-social problems reported. Lastly, it should be noted that a healthy worker effect cannot be excluded as a partial explanation for the findings, particularly given the cross-sectional nature of the data.

Longer-term studies can provide a clearer understanding of the health of these women as they get older. To assess the validity of the findings, more in-depth probes of the problems will be helpful.
Using designs and study methods more integrally involving the workers themselves may be required to identify the true occurrence of more sensitive health problems. .

\section{Conclusion}

Relative to studies of other occupational groups in middle income countries, these female garment workers reported overall good health; their most notable problem was musculoskeletal symptoms. The findings could represent adequate control of work-related risks, but a healthy worker effect and social desirability bias must also be considered as explanations for the positive health status of these relatively young workers.

\section{Acknowledgement}

This study was funded by the Hubert Yeargen Center for Global Health and Duke Global Health Institute. The authors extend their appreciation to the women who participated in this study.

\section{References}

1. Bharathi D. Tears of the emerald isle: women garment workers in EPZs of Sri Lanka: Committee for Asian Women 2007.

2. Central Bank of Sri Lanka. Annual Report 2006. Retrieved January 25, 2011, http://www.cbsl.gov.lk/index.asp

3. Attanapola CT. (2004). Changing gender roles and health impacts among female workers in export-processing industries in Sri Lanka. Social Science \& Medicine 2004; 58(11): 2301-2312.

4. Hancock P, Middleton S, Moore J. Export Processing Zones (EPZs), globalization, feminised labour markets and working conditions: a study of Sri Lankan EPZ workers. Labour and Management in Development, 2009.

5. Samarasinghe V. The Feminization of Foreign Currency Earnings: Women's Labor in Sri Lanka. The Journal of Developing Areas 1998; 32(3): 303-326.

6. Busser E. Labour standards and trade preferences in Sri Lanka Dialogue on globalization: Friedrich Ebert Stiftung (FES) 2005.

7. Chand A. Physical and psychological health problems of garment workers in the Fiji. Pacific Public Health 2006; 13(2): 65-70. 
8. Joseph B, Kiran PR. A stitch in time... annual health appraisal of garment industry employees. Pak J Med Sci 2008; 24(1): 104-108.

9. Descatha A, Roqulaure Y, Evanoff B, Mariel J, Leclerc A. Predictive factors for incident musculoskeletal disorders in an in-plant surveillance program. Ann Occup Hyg 2007; 51(3): 337-344.

10. Choobineh A, Tabatabaee SH, Behzadi M. Musculoskeletal Problems Among Workers of an Iranian Sugar-Producing Factory. International Journal of Occupational Safety and Ergonomics 2009; 15(4): 419-424.

11. Lynch C. Juki Girls, Good Girls: Gender and cultural politics in Sri Lanka's global garment industry. New York: IRLPress 2007.

12. Jiang CQ, Lam TH, Kong C, Cui CA, Huang HK, Chen DC, Chen YH. (1995). Byssinosis in Guangzhou, China. Occupational and Environmental Medicine 1995; 52(4); 268-272.

13. Wang X-R, Eisen EA, Zhang H-X, Sun B-X, Dai H-L, Pan L-D, Christiani DC. Respiratory symptoms and cotton dust exposure; results of a 15 year follow up observation. Occupational and Environmental Medicine 2003; 60(12): 935-941.

14. Wang X-R, Zhang H-X, Sun B-X, Dai H-L, Hang J-Q, Eisen EA. Christiani DC. A 20-year follow-up study on chronic respiratory effects of exposure to cotton dust. European Respiratory Journal 2005; 26(5): 881-886.
15. Shi J, Mehta AJ, Hang J-q, Zhang H, Dai H, Su L, Christiani DC. Chronic Lung Function Decline in Cotton Textile Workers: $\ddot{A} \circledast$ Roles of Historical and Recent Exposures to Endotoxin. Environ Health Perspect 2010; 118(11).

16. Somasiri KG, Gunawardena S, Wijesiri WAA, Mendis ALS, Jayawardena R. Assessment of quality of life using sinhala translation of WHO QOL 100. Galle Medical Journal 2003; Oral presentation 8 .

17. Gamperiene M, Stigum H. Work related risk factors for musculoskeletal complaints in the spinning industry in Lithuania. Occupational and Environmental Medicine 1999; 56(6): 411-416.

18. Sarder M, Imrhan S, Mandahawi N. Ergonomic workplace evaluation of an Asian garment-factory. J Human Ergol 2006; 35: 45-51.

19. Perera GSN, Jayawardena PL, Senanayaka AES, Samarage SM. HHQ Sri Lanka: A screening instrument to determine migraine and tension type headache in the community. Annual Academic Sessions, Sri Lanka Medical Association.

20. Raza SN, Fletcher AM, Pickering CAC, Niven RM, Faragher EB. Respiratory Symptoms in Lancashire Textile Weavers. Occupational and Environmental Medicine 1999; 56(8): 514-519. 